\title{
Polystyrene/High Density Polyethylene Blends Compatibilized by Tri-Block Copolymer II. Toughening and Deformation Mechanisms
}

\author{
Shi-Ai Xu and Chi-Ming $\mathrm{CHAN}^{\dagger}$ \\ Department of Chemical Engineering, Advanced Engineering Materials Facility, \\ The Hong Kong University of Science and Technology, \\ Clear Water Bay, Hong Kong
}

(Received November 26, 1997)

\begin{abstract}
A dilatometry method was applied to study the tensile deformation mechanisms of polystyrene/high density polyethylene (80/20) blends compatibilized by different amounts of a styrene-ethylene-butylene-styrene tri-block copolymer (SEBS). The volume change of the sample during uniaxial tensile process, which was determined by two extensometers, was found to be related to the various modes of deformation. To obtain quantitative information on the separate contributions of several possible deformation modes to the total deformation, a simple model proposed by Dekkers and Heikens was used in this study. For comparison, the tensile behaviors of the pure polystyrene and high density polyethylene were investigated also. The results indicated that elastic deformation was the main deformation mode for pure polystyrene and the uncompatibilized blend; whereas, plastic deformation was found to play an important role in a tensile process of the compatibilized blends. For the blend containing $2 \mathrm{wt} \%$ SEBS, the deformation process was very complex, crazing and shearing predominated alternatively in different ranges of strain. However, shearing was the main non-Hookean deformation mechanism for the blends containing SEBS content higher than $4 \mathrm{wt} \%$. The different deformation characteristics of the blends were related to their morphologies. KEY WORDS Dilatometry / Deformation Mechanism / Crazing / Shearing / Polystyrene / Polyethylene / Blends / Styrene-Ethylene-Butylene-Styrene Tri-Block Copolymer /
\end{abstract}

Glassy polymers constitute a large group of industrially important materials for structural applications; however, these materials tend to fracture in a brittle manner, greatly limiting their applications. ${ }^{1-4}$ Great efforts have been made to improve the brittleness of these polymers. It is well known that polystyrene is a typical glassy polymer with high strength, high modulus, and excellent dimensional stability. Attempts to toughen it have resulted in a series of industrial products with desirable toughness, such as high impact polystyrene and acrylonitrile-butadiene-styrene copolymer.

The traditional way to toughen plastics is to disperse an elastomer into the brittle polymer matrix. Based on a large number of investigations on deformation mechanisms by transmission electron microscopy (TEM), a relatively good understanding of the toughening mechanisms of rubber-toughened systems has been achieved. In these polymer blends, the dispersed rubber particles act as stress concentrators. When the materials are subjected to an external tension or impact, crazes are initiated at the periphery of the rubber particles. These crazes absorb a large amount of energy, resulting in greatly improved toughness of the materials. ${ }^{1,5,6}$ The rubber particles play an important role in initiating and controlling the crazes. However, the incorporation of a low modulus rubbery component generally results in a sharp decrease in both the modulus and processability of the blend. Therefore, in the last decades, toughening a brittle polymer by blending it with a tough plastic instead of a rubber has been extensively studied. ${ }^{7-10}$

In recent decades, toughening polystyrene (PS) with polyethylene (PE) has become a subject of considerable research and development efforts. ${ }^{11}$ These studies focused on the compatibilization technology and relationship between properties and morphology. However, little

$\dagger$ To whom correspondence should be addressed. information on the toughening mechanisms of these materials was reported in the literature. By using a solution-melt procedure, $\mathrm{Xu}$ and Jiang et al. $^{4}$ studied the deformation process of the blends of PS and low density polyethylene (LDPE) with a styrene-ethylenebutylene-styrene tri-block copolymer (SEBS) as the compatibilizer by in situ stretching using TEM equipped with a mini tensile stage. For the PS/LDPE (80/20) blend, the crazing of the PS matrix is the main toughening mechanism, and the initiation and propagation processes of the crazes are similar to those of rubber toughened plastics. The termination of the crazes is probably associated with the shear deformation of the LDPE particles to which the crazes attach. For the PS/LDPE $(20 / 80)$ blend, localized shearing of the matrix becomes the main deformation mode. However, the conclusions drawn from the ultra-thin film study may not be applicable to thick samples. In addition, although TEM is unique in its ability to positively identify the specific mechanisms, it cannot be used to determine quantitatively the contributions of various competing mechanisms to the total deformation. ${ }^{12}$

The volume change of a polymer specimen in a tensile process can be used to reveal the microscopic mechanisms. Bucknall and Clayton ${ }^{12,13}$ used this method to analyze the creep data and demonstrated its usefulness as a means to study the deformation process of rubbertoughened plastics. Using a liquid-displacement stress dilatometer, Schwarz ${ }^{14}$ studied the volume change of immiscible blends of high density polyethylene (HDPE) and an amorphous glassy phase consisting of either pure polystyrene or a miscible blend of PS and polyether copolymer (PEC) during uniaxial mechanical straining. The volume change was shown to be related to various modes of deformation. They found that a craze-to-shear yielding transition occurred at the PS content between 40 and $60 \mathrm{wt} \%$ for the miscible blends of PEC and PS, 
and the transition occurred at higher PS concentrations as SEBS was added. Blends with a HDPE matrix and a dispersed glassy phase showed smaller volume expansions after the addition of SEBS and the volume expansions were substantially less in the blends with a PEC/PS glassy phase instead of pure PS. However, they did not make a quantitative analysis on the contribution of the different deformation processes.

In a previous paper, ${ }^{15}$ the toughened PS blends were produced by using HDPE as a toughening modifier and choosing SEBS as a compatibilizer. The tensile test results suggested that the elongation-at-break and the fracture energy, which were greatly improved after addition of the copolymer into PS/HDPE blends, increased with an increase in the block copolymer content. In this paper, the dilatometry method was used to study the tensile deformation mechanisms of the PS/HDPE blends. The volume changes of the sample in a tensile process were calculated according to the longitudinal and transverse strains which could be measured by two extensometers. The contributions of the different deformation mechanisms to the total deformation were quantitatively determined by a simple model proposed by Bucknall and Clayton. ${ }^{12,13}$ This model, originally applied to analyze data for creep experiments, ${ }^{12,13}$ has been successfully used to analyze data for tensile experiments. ${ }^{16}$

\section{EXPERIMENTAL}

\section{Materials}

The homopolymers used in this study were a commercial grade of PS (Styron GP66 HR3DOW, Dow Chemical Pacific Ltd.) and HDPE (Phillips 66, Marlex HMN 6060, melt index: $6.5 \mathrm{~g} \mathrm{~min}^{-1}$, Phillips Chemical Company). The molecular weights of PS and HDPE were determined by gel permeation chromatography. The number-average and weight-average molecular weights of PS were determined to be 78450 and 232900 , respectively. The number-average and weight-average molecular weights of HDPE were determined to be 14700 and 61900, respectively. SEBS (G1652) was kindly supplied by Shell company, and the respective molecular weights of the PS block and the central EB block are 7500 and 37500 , respectively and the PS weight fraction is $28.6 \%$.

\section{Blending and Sample Preparation}

The homopolymers and SEBS were dried for $24 \mathrm{~h}$ at 80 and $60^{\circ} \mathrm{C}$, respectively. The blends were prepared by mixing the well-dried pellets in a twin-screw extruder (Haakè Rheometer 9000) with a $\mathrm{L} / \mathrm{D}$ ratio of 10 , operating at $30 \mathrm{rpm}$. To ensure thorough mixing, the pellets from the first extrusion were sent through the extruder for another run. The temperatures in the three heating zones were 170,180 , and $190^{\circ} \mathrm{C}$. The temperature at the die was $200^{\circ} \mathrm{C}$. The composition of the blends was fixed at a weight ratio of $80 / 20$ (PS/HDPE), and the SEBS content varied from 0 to $10 \mathrm{wt} \%$, being defined with respect to the total weight of the blend.

The extrudates were pelletized and then dried at $80^{\circ} \mathrm{C}$ for $24 \mathrm{~h}$. Dumb-bell shape tensile bars (ASTM D638-91, type IV) were injection molded using a Morgan hot press. The temperatures at barrel and nozzle were 210 and $220^{\circ} \mathrm{C}$, respectively.

\section{Measurement}

Tensile measurements were carried out at room temperature $\left(21^{\circ} \mathrm{C}\right)$ using an Instron tensile tester (Model 5567 ) at a cross-head speed of $10 \mathrm{~mm} \mathrm{~min}^{-1}$. In the test, two highly sensitive extensometers were employed to measure the longitudinal and transverse (width) strains simultaneously. The measurement errors for the longitudinal and transverse strains were $\pm 0.18 \%$ of the gauge length and $\pm 0.13 \%$ of full scale deflection, respectively. To avoid the damage of the extensometers caused by the abrupt vibration during tensile tests, the experiments were stopped prior to the final failure of specimens.

\section{RESULTS AND DISCUSSION}

Many techniques can be used to measure the volume change of a sample in a tensile process. ${ }^{12,13,17-21}$ In the present study, the volume strain was determined from the following equation assuming that the thickness strain is the same as the width strain. ${ }^{22,23}$ This assumption, though approximate, is believed to be adequate to determine the deformation mechanisms ${ }^{2}$

$$
\frac{\Delta V}{V}=\left(1+\varepsilon_{1}\right)\left(1+\varepsilon_{\mathrm{t}}\right)^{2}-1
$$

where $\Delta V$ is the change in volume, $V$ is the original volume, the ratio, $\Delta V / V$, is the volume strain, and $\varepsilon_{1}$ and $\varepsilon_{\mathrm{t}}$ are the longitudinal and transverse engineering strains, respectively.

Figure 1 shows typical curves of engineering stress and volume strain versus elongation strain for PS. It can be seen that pure PS exhibits a tensile behavior typical of brittle polymers. It fractured in a brittle mode and no yield point appeared before the final break. ${ }^{15}$ In the range of strain studied, the volume strain for pure PS increases linearly with the longitudinal strain. Similar situation was observed also for the uncompatibilized blend ( $c f$. Figure 2).

The curves showing the engineering stress and volume strain versus the longitudinal strain for the blends compatibilized by different amounts of SEBS are displayed in Figure 3. The results indicate that the compatibilized blends exhibit a ductile behavior, and attain greater ultimate elongations. ${ }^{15}$ However, only the blend containing $2 \mathrm{wt} \%$ SEBS shows a distinct yield point on its stress-strain curve. On the other hand, the volume dilation response curves of the compatibilized blends are not linear, indicating that the deformation mechanisms for these blends are somewhat complex.

Figure 4 shows the engineering stress and volume change versus the elongation strain for HDPE. HDPE is known to exhibit a ductile behavior during extension. As reported in the previous paper, ${ }^{15}$ necking appeared in the tensile process of HDPE. When the neck propagated through the entire gauge part, the specimen broke and the ultimate elongation was about $1100 \%$. It is worth noting that no stress whitening was observed during the necking process. It is interesting that the volume strain of HDPE first increases with elongation strain due to the elastic response (Poisson's effect) of the sample. ${ }^{24,25}$ Then the volume strain decreases and be- 


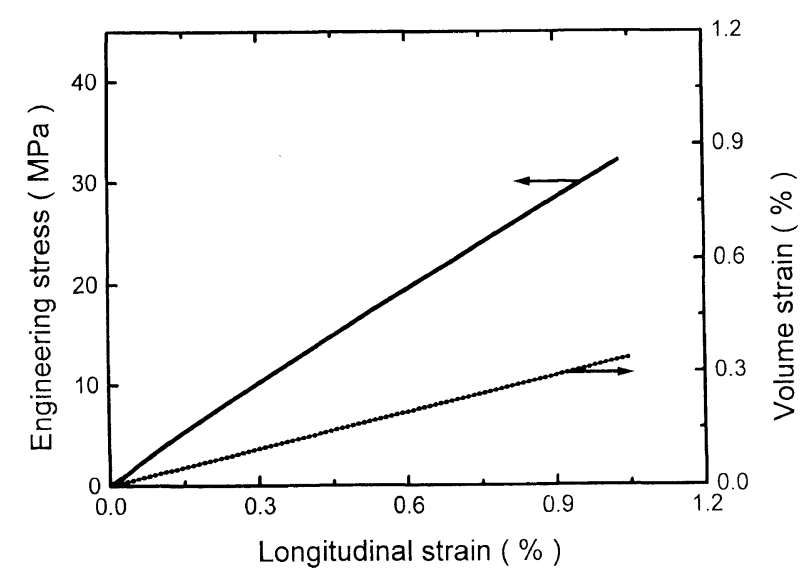

Figure 1. Plots of engineering stress and volume strain versus longitudinal strain for pure polystyrene.

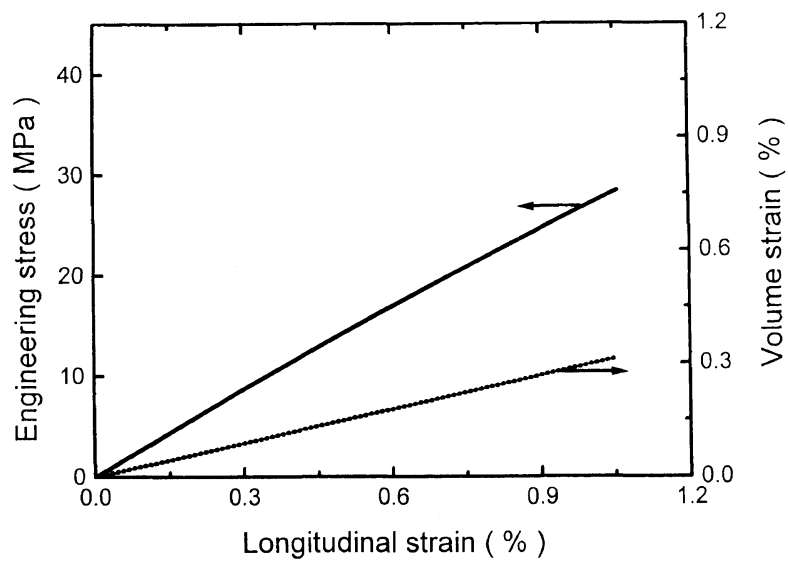

Figure 2. Plots of engineering stress and volume strain versus longitudinal strain for uncompatibilized PS/HDPE (80/20) blend.

comes negative when the strain exceeds $4 \%$. Similarly, Bucknall et al. ${ }^{26}$ investigated the tensile deformation behavior of semi-crystalline nylon and found that nylon showed a progressive slow decrease in volume with increasing tensile strain. At an elongation strain of $40 \%$, the volume strain is $-1.4 \%$. These findings were attributed to an increase in crystallinity within the shear zones.

In order to determine the separate contributions of the elastic deformation, shear deformation and crazing to the total elongation, a quantitative model proposed by Heikens et al. ${ }^{16,17}$ was adopted in this paper. In this simple model, the respective contributions of elastic deformation, shear deformation and crazing to the total elongation strain and the total volume strain are assumed to be additive, and the amount of material which is deforming elastically remains constant during the entire tensile process. Furthermore, it is assumed that shear deformation makes a negligible contribution to the volume strain. And the volume strain caused by crazing is assumed to be equal to the elongation strain caused by crazing. In addition, crazing is assumed to be the only cavitation mechanism and other cavitation processes are neglected. However, debonding at the interface and cavitation of SEBS could also contribute to the volume strain. According to this model, at any elongation strain, the strains caused by elastic deformation $\left(\varepsilon_{\mathrm{el}}\right)$, shear deformation $\left(\varepsilon_{\mathrm{sh}}\right)$, and crazing $\left(\varepsilon_{\mathrm{cr}}\right)$ can be calculated Polym. J., Vol. 30, No. 9, 1998
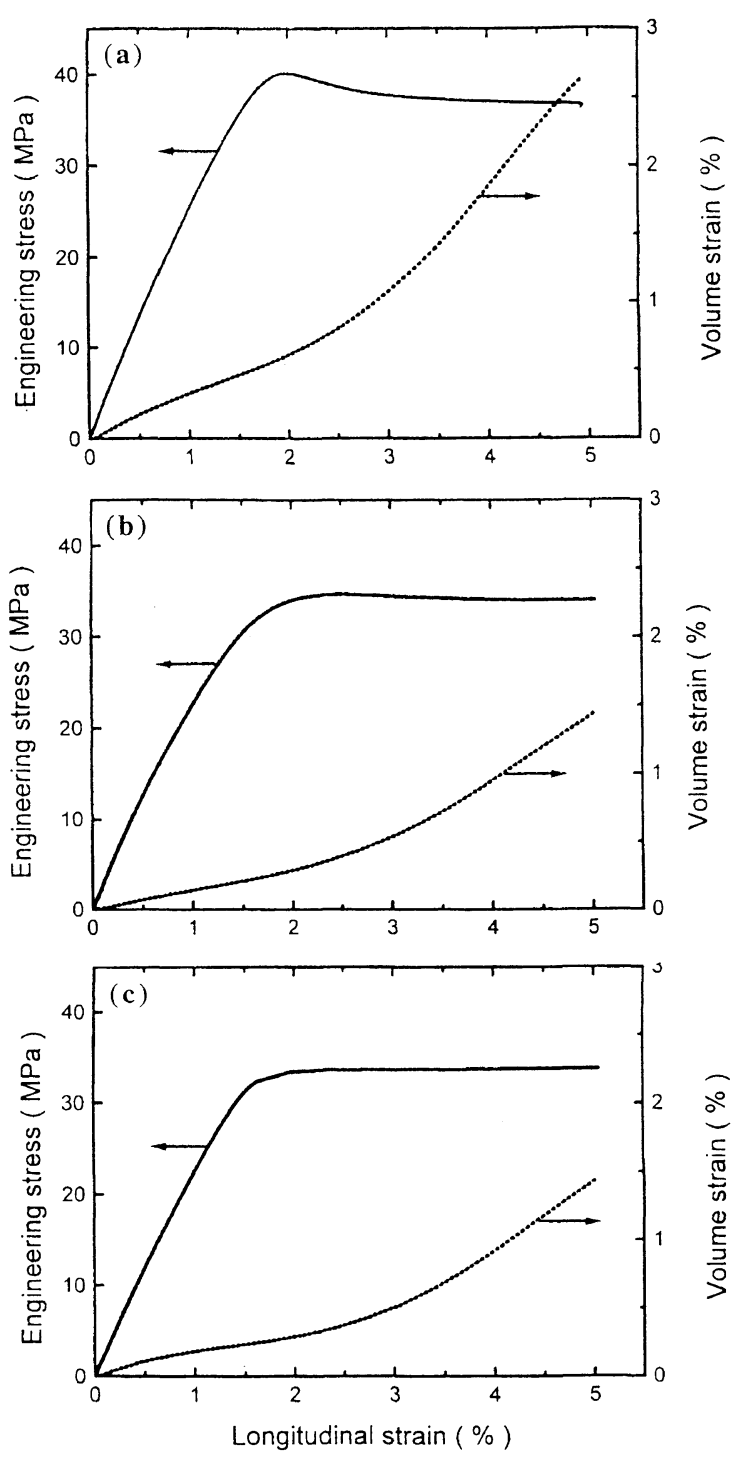

Figure 3. Plots of engineering stress and volume strain versus longitudinal strain for PS/HDPE (80/20) blends compatibilized by (a) $2 \mathrm{wt} \%$ of SEBS, (b) $4 \mathrm{wt} \%$ of SEBS, and (c) $8 \mathrm{wt} \%$ of SEBS.

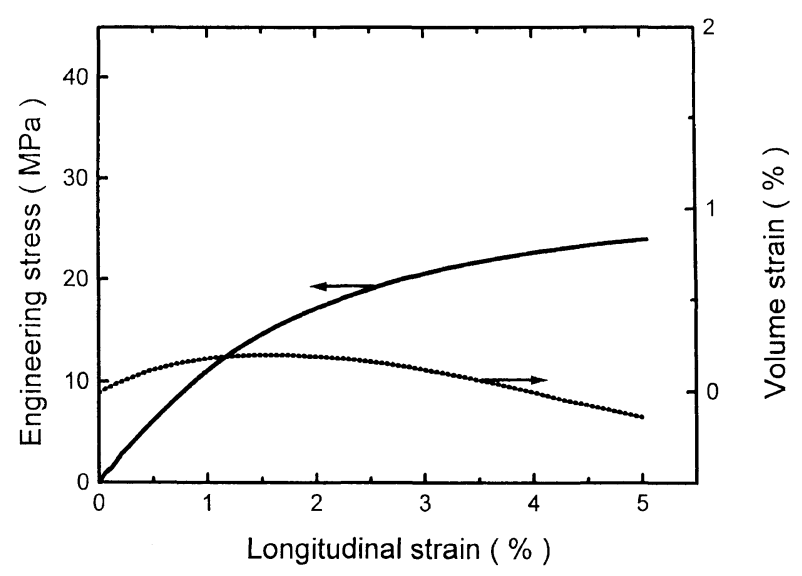

Figure 4. Plots of engineering stress and volume strain versus longitudinal strain for pure HDPE.

from the $\sigma_{\mathrm{T}}-\varepsilon-\Delta V / V$ diagrams and are given by the following equations ${ }^{27}$ :

$$
\varepsilon_{\mathrm{el}}=\frac{\sigma_{\mathrm{T}}}{E},
$$




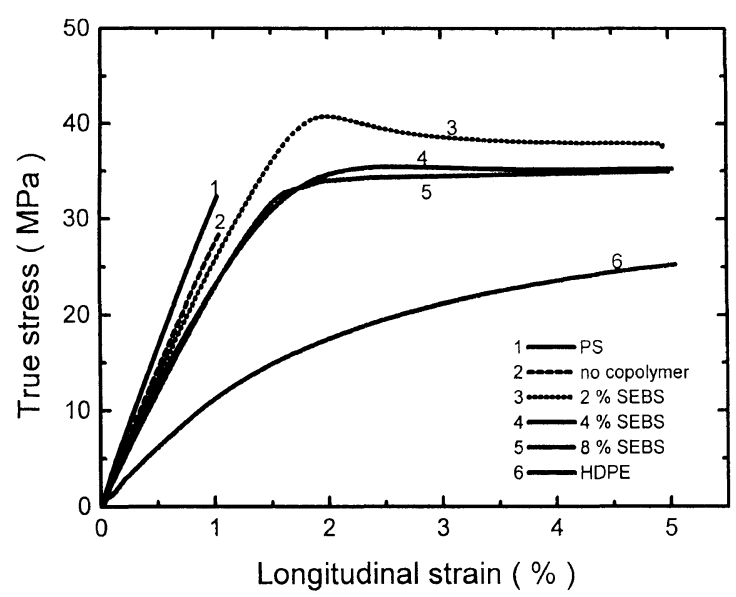

Figure 5. True stress-strain curves for (a) pure PS, (b) uncompatibilized PS/HDPE (80/20) blend, (c) PS/HDPE (80/20) blend compatibilized by $2 \mathrm{wt} \%$ SEBS, (d) PS/HDPE ( $80 / 20)$ blend compatibilized by 4 wt $\%$ SEBS, (e) PS/HDPE (80/20) blend compatibilized by $8 \mathrm{wt} \%$ SEBS, and (f) pure HDPE.

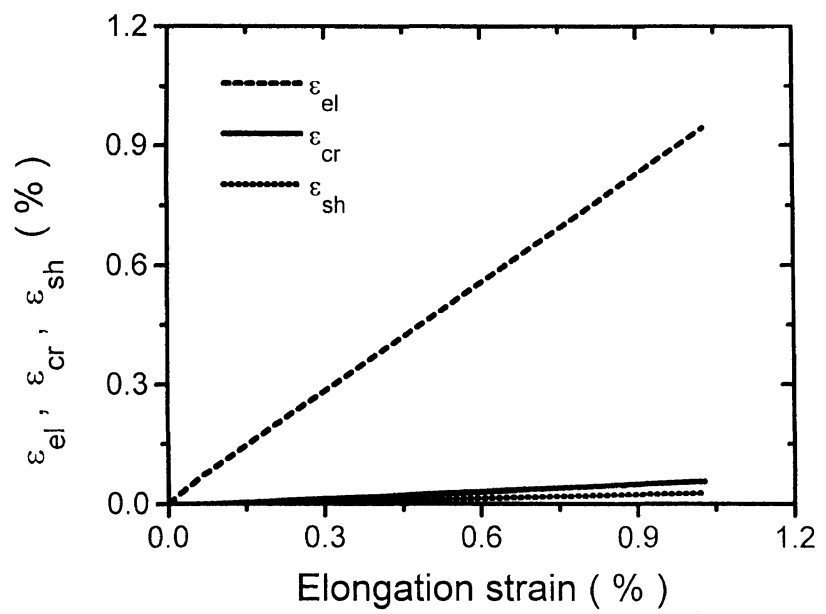

Figure 6. Plots of the elongation strains caused by elastic deformation, shear deformation, and crazing versus the total elongation strain for pure PS.

$$
\begin{gathered}
\varepsilon_{\mathrm{cr}}=\frac{\Delta V}{V}-\frac{(1-2 v) \sigma_{\mathrm{T}}}{E}, \\
\varepsilon_{\mathrm{sh}}=\varepsilon-\frac{\Delta V}{V}-\frac{2 v \sigma_{\mathrm{T}}}{E},
\end{gathered}
$$

where $\sigma_{\mathrm{T}}$ is the true stress, $E$ is Young's modulus, $\varepsilon$ is the elongation strain, and $v$ is the Poisson's ratio. $E$ and $v$ can be calculated from the initial slopes of $\sigma_{\text {eng }}-\varepsilon\left(\sigma_{\text {eng }}\right.$ is the engineering stress) and $\varepsilon_{\mathrm{t}}-\varepsilon$ curves, respectively. The true stress is calculated using the instantaneous cross-sectional area over which the deformation occurs. The relation between the true and engineering stresses is

$$
\sigma_{\mathrm{T}}=\frac{\sigma_{\mathrm{eng}}}{\left(1+\varepsilon_{\mathrm{t}}\right)^{2}}
$$

The curves showing the true stress versus the elongation strain for PS, HDPE, and their blends are displayed in Figure 5.

The elongation strains caused by the elastic deformation, shear deformation and crazing as a function of the total longitudinal strain for PS are shown in Figure 6. It can be seen that elastic deformation is the dominant

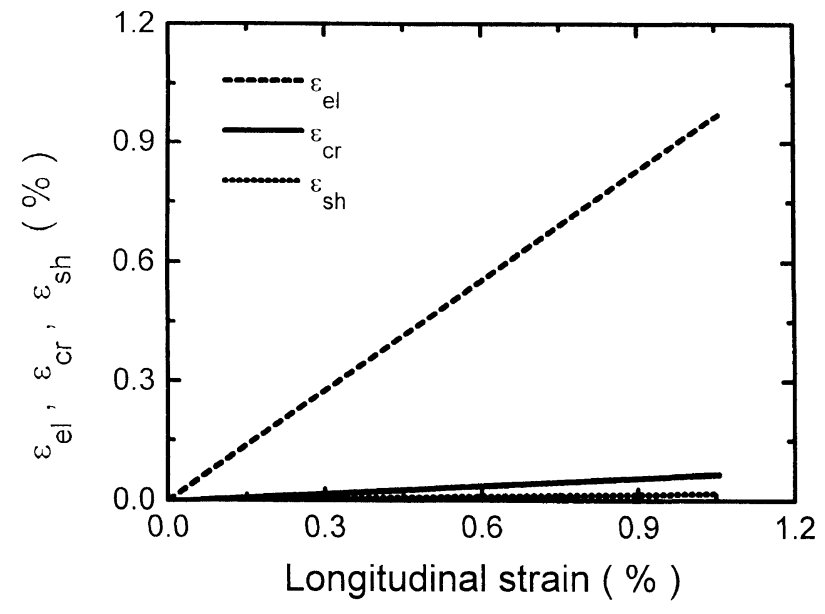

Figure 7. Plots of the elongation strains caused by elastic deformation, shear deformation, and crazing versus the total elongation strain for the uncompatibilized PS/HDPE $(80 / 20)$ blend.

deformation mechanism over the whole strain range studied. The deformations produced by crazing and shearing are minute relative to the elastic deformation. It is also noted that the critical strain to initiate crazes is smaller than that required to induce shear deformation for PS. It is well known that the plastic deformation of glassy polymers may advance either by shearing or crazing, ${ }^{28}$ depending mainly on the critical strain (or stress) that is required to initiate it. Generally, the crazing occurs at lower applied stresses than shearing for PS. Thus crazing is the main plastic deformation mode of PS in a tensile process.

Figure 7 shows the separate contributions of the elastic deformation, shear deformation and crazing in the tensile process for the uncompatibilized PS/HDPE (80/20) blend. It is evident that elastic deformation still predominates, but crazing is obviously larger than shear deformation. Moreover, crazing initiates at a much lower strain than the shear deformation. As mentioned in the previous paper, ${ }^{15}$ the HDPE component is dispersed as spherical particles in the PS matrix for the uncompatibilized PS/HDPE (80/20) blend. The spherical HDPE particles act as stress concentrators in the tensile process, thereby resulting in a much lower applied stress required to start the crazing. In this case, crazing appears to occur more easily. Therefore, the uncompatibilized PS/HDPE $(80 / 20)$ blend displays a larger volume change than pure PS. The interfacial adhesion between PS and HDPE is very weak because they are incompatible. The crazes, which are initiated at the surface of the HDPE particles, easily develop into cracks, resulting in the final fracture. Therefore crazing contributes a small part to the total elongation.

When $2 \mathrm{wt} \%$ SEBS was added to the PS/HDPE (80/20) blend, a completely different phenomenon occurred (Figure 10). As mentioned previously, elastic deformation is obtained by the true stress divided by Young's modulus; therefore, the variation of the elastic deformation with the longitudinal strain shows the same trend as the true stress versus strain curve. The abrupt decrease in elastic deformation should correspond to the yield point in the plot of true stress versus strain. Figure 8 shows that elastic deformation is the main deformation 


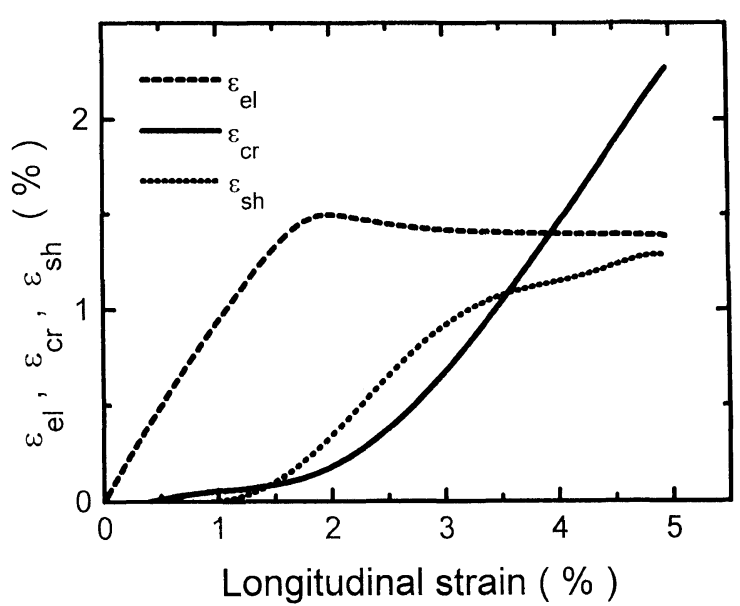

Figure 8. Plots of the elongation strains caused by elastic deformation, shear deformation, and crazing versus the total elongation strain for the PS/HDPE (80/20) blend compatibilized by $2 \mathrm{wt} \%$ SEBS.

mode before the yield point. After that, plastic deformations (including crazing and shearing) increase, and eventually become the dominant deformation mode. Moreover, it is apparent that crazing deformation is the dominant plastic deformation mechanism at low elongation strains (less than 1.4\%), and the shear deformation occurs at a strain of about $1.0 \%$. As the strain exceeds $1.4 \%$, shear deformation is larger than crazing. However, crazing becomes predominant again when the elongation strain exceeds $3.5 \%$. Crazing needs a long initiation period-it starts at a strain less than $0.5 \%$, but only becomes significant after the strain exceeds $2.0 \%$. In the previous paper, ${ }^{15}$ it was examined that in the PS/HDPE blend compatibilized by $2 \mathrm{wt} \%$ SEBS, the HDPE particles were homogeneously dispersed in the PS matrix. The mechanical properties suggested that strong adhesion existed between two phases. When the specimen was strained, the crazes were first initiated at the periphery of these spherical HDPE particles. Then, the applied stresses were transferred from the matrix to the dispersed HDPE particles because of strong interfacial adhesion. Hence, cracks did not easily form at the interfaces but crazes developed, preventing the fatal break. Meanwhile, the dispersed HDPE particles were deformed by shear due to the stress transferred through the interfaces. Therefore, these two kinds of plastic deformation occurred simultaneously in the tensile process of the specimen as shown in Figure 4.

Using a solution-melt procedure, $\mathrm{Xu}$ and Jiang $\mathrm{et}_{\mathrm{al}}{ }^{3}$ studied the deformation process of PS/LDPE/SEBS blends by TEM. They observed that for the PS/LDPE $(80 / 20)$ blend with $10 \mathrm{wt} \%$ SEBS as the compatibilizer, crazing of the PS matrix was the main deformation mode. Meanwhile, the LDPE particles dispersed in the PS matrix were deformed by shearing. Based on these results, it can also be inferred that the shear deformation, as shown in Figure 8, is a result of the shear deformation of the HDPE particles.

The plots of elongation strains due to elastic deformation, shear deformation and crazing versus the total elongation strain for the PS/HDPE (80/20) blend compatibilized by $4 \mathrm{wt} \%$ of SEBS is shown in Figure 9. Similar to the blend containing $2 \mathrm{wt} \%$ SEBS, elastic deformation is the main deformation mode before

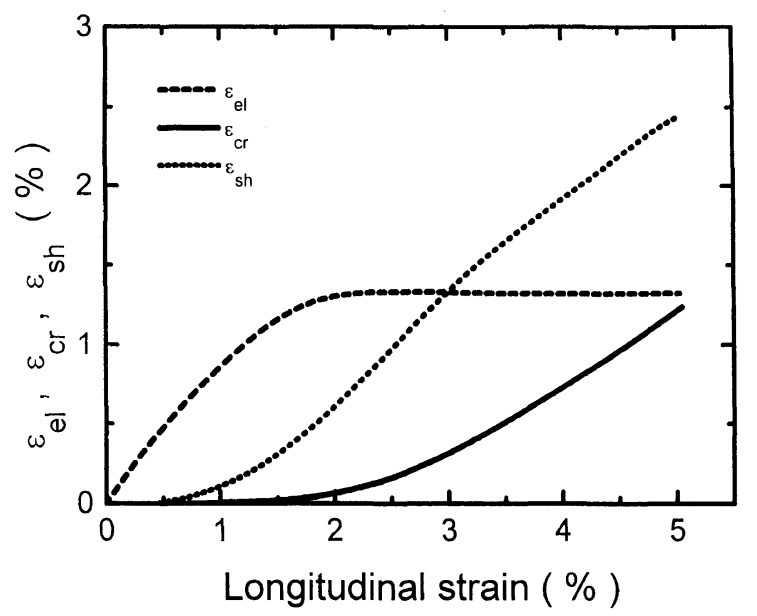

Figure 9. Plots of the elongaton strains caused by elastic deformation, shear deformation, and crazing versus the total elongation strain for the PS/HDPE (80/20) blend compatibilized by $4 \mathrm{wt} \%$ SEBS.

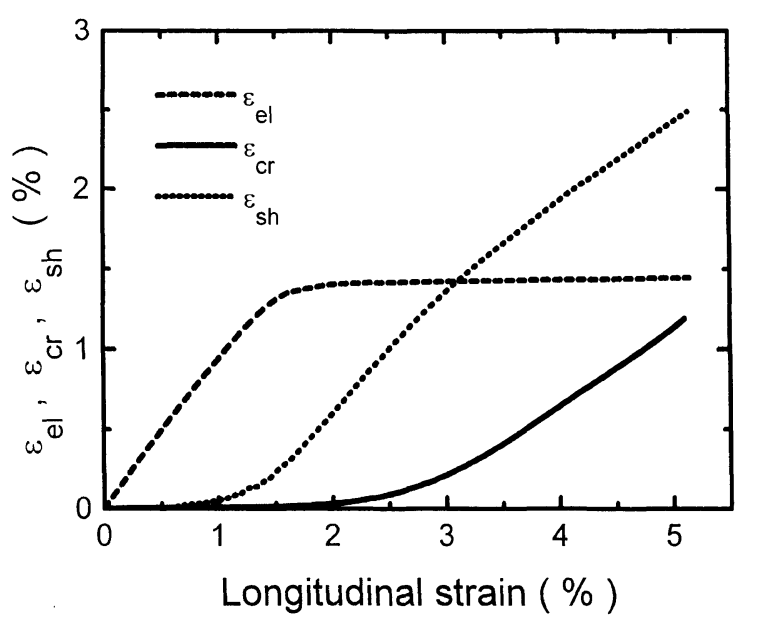

Figure 10. Plots of the elongation strains caused by elastic deformation, shear deformation, and crazing versus the total elongation strain for the PS/HDPE $(80 / 20)$ blend compatibilized by $8 \mathrm{wt} \%$ SEBS.

the yield point. After that, plastic deformation becomes the predominant mode. Crazing initiates at a relatively higher strain (about $1.0 \%$ ) and shear deformation becomes the dominant plastic deformation mechanism (Figure 9). According to the SEM results, the blend compatibilized by $4 \mathrm{wt} \%$ of SEBS exhibits a bi-continuous two-phase structure. ${ }^{15}$ When this blend specimen was strained, the continuous HDPE phase is deformed by shearing at lower strains and crazing of the PS phase initiates at higher strains. A similar situation is found in the blend containing $8 \mathrm{wt} \%$ SEBS owing to the similarity of their morphologies ${ }^{15}$ (Figure 10).

Because of the crystallinity change in a tensile process of HDPE, the volume strain of HDPE, as shown in Figure 4, does not represent the real volume change caused by several possible deformation modes; therefore, this model cannot be used to determine quantitatively the deformation mechanisms of HDPE. In fact, for any polymer, the orientation of molecular chains is unavoidable, resulting in an increase in the density of the polymer. Therefore, the measured values of $\Delta V$ underestimate the actual amount of voiding in the polymer blends during a tensile process. ${ }^{26}$ 


\section{CONCLUSIONS}

1. The simple quantitative model developed by Heikens et al. can be used to analyze the tensile deformation mechanisms of pure PS and PS/HDPE blends compatibilized by different amounts of SEBS. The separate contributions of elastic deformation, shear deformation, and crazing to the total elongation can be obtained. However, the model is not suitable for HDPE owing to the large change in the density in a tensile process.

2. For PS, which is a brittle polymer, the critical strain required to start crazing is considerably lower than that required to induce shear deformation. Therefore, crazing is the main non-elastic deformation mode of PS in a tensile process.

3. In a tensile process of the uncompatibilized PS/ HDPE (80/20) blend, the elastic deformation predominates over the entire strain range studied. However, among the plastic deformations, crazing is obviously larger than shear deformation.

4. For the blends compatibilized by SEBS, crazing and shearing both contribute to the total deformation. However, the elastic deformation is the main deformation mode before yield point, and after that, the plastic deformation increases significantly, and progressively becomes predominant. For the blend containing $2 \mathrm{wt} \%$ of SEBS, crazing and shearing predominate alternatively, and for the blends with SEBS content higher than $4 \mathrm{wt} \%$, shearing deformation is always larger than crazing.

\section{REFERENCES}

1. E. J. Krammer, Adv. Polym. Sci., 52/53, 1 (1983).

2. A. S. Argon and C. E. Cohen, Adv. Polym. Sci., 91/92, 1 (1990).
3. S. A. Xu, M. Jiang, and J. S. Shen, Polym. J., 28, 2269 (1996).

4. S. A. Xu, M. Jiang, and J. S. Shen, Polym. J., 27, 607 (1995).

5. A. Donald and E. J. Krammer, J. Mater. Sci., 17, 1871 (1982).

6. T. Kyu, J. M. Saldanha, and M. J. Kiesel, in "Two-Phase Polymer Systems," L. A. Utraki, Ed., Hanser Publisher, New York, N.Y., 1991, Chapter 10, p 259.

7. R. Fayt, R. Jerome, and Ph. Teyssie, J. Polym. Sci., Polym. Lett. Ed., 19, 79 (1981).

8. M. C. Schwarz, J. W. Barlow, and D. R. Paul, J. Appl. Polym. Sci., 35, 2053 (1988).

9. T. Appleby, F. Cser, G. Moad, E. Rizzardo, and C. Stavropoulos, Polym. Bull., 32, 479 (1994).

10. H. Ravel, Surekha Devi, Y. P. Singh, and M. H. Mehta, Polymer, 32, 493 (1991).

11. Z. Wang, C. M. Chan, S. H. Zhu, and J. R. Shen, Polymer, accepted.

12. C. B. Bucknall and D. Klayton, J. Mater. Sci., 7, 202 (1972).

13. C. B. Bucknall and D. Klayton, Nature, 231, 107 (1971).

14. J. M. C. Schwarz, H. Keskkula, J. W. Barlow, and D. R. Paul, J. Appl. Polym. Sci., 35, 653 (1988).

15. S. A. Xu and C. M. Chan, Polym. J., 30, 552 (1998).

16. D. Heikens, S. D. Sjoerdsma, and W. J. Counians, J. Mater. Sci., 16, 429 (1981).

17. C. B. Bucknall, D. Klayton, and W. Keast, J. Mater. Sci., 8, 514 (1973).

18. R. W. Truss and G. A. Chadwick, J. Mater. Sci., 11, 111 (1976).

19. R. W. Truss and G. A. Chadwick, J. Mater. Sci., 11, 1385 (1976).

20. L. C. Cessna, Polym. Eng. Sci., 14, 696 (1974).

21. W. J. Coumans and D. Heikens, Polymer, 21, 957 (1980).

22. D. S. Parker, R. J. Sue, J. Hung, and A. F. Yee, Polymer, 31, 2267 (1990).

23. S. I. Nagui and I. B. Robinson, J. Mater. Sci., 28, 1421 (1993).

24. H. J. Sue and A. F. Yee, J. Mater. Sci., 24, 1447 (1989).

25. M. E. J. Dekkers, S. Y. Hobbs, and V. H. Watkins, J. Mater. Sci., 23, 1225 (1988).

26. C. B. Bucknall, P. S. Heather, and A. Lazzer, J. Mater. Sci., 16, 2255 (1989).

27. M. E. J. Dekkers and D. Heikens, J. Appl. Polym. Sci., 30, 2389 (1985).

28. C. B. Bucknall, "Toughened Plastics," Applied Science Publisher, London, 1977. 